\title{
A Methodology for Determination of Resilient Modulus of Asphaltic Concrete
}

\author{
A. Patel, ${ }^{1}$ M. P. Kulkarni, ${ }^{2}$ S. D. Gumaste, ${ }^{2}$ P. P. Bartake, ${ }^{2}$ K. V. K. Rao, ${ }^{3}$ and D. N. Singh ${ }^{2}$ \\ ${ }^{1}$ Department of Civil Engineering, VSS University of Technology, Burla 768018, India \\ ${ }^{2}$ Geotechnical Engineering Division, Department of Civil Engineering, Indian Institute of Technology Bombay, Powai, \\ Mumbai 400 076, India \\ ${ }^{3}$ Transportation Engineering Division, Department of Civil Engineering, Indian Institute of Technology Bombay, Powai, \\ Mumbai 400 076, India
}

Correspondence should be addressed to D. N. Singh, dns@civil.iitb.ac.in

Received 29 December 2010; Accepted 7 March 2011

Academic Editor: Nagaratnam Sivakugan

Copyright (C) 2011 A. Patel et al. This is an open access article distributed under the Creative Commons Attribution License, which permits unrestricted use, distribution, and reproduction in any medium, provided the original work is properly cited.

\begin{abstract}
Resilient modulus, $M_{R}$, is an important parameter for designing pavements. However, its determination by resorting to cyclic triaxial tests is tedious and time consuming. Moreover, empirical relationships, correlating $M_{R}$ to various other material properties (namely, California Bearing Ratio, CBR; Limerock Bearing Ratio, LBR; R-value and the Soil Support Value, SSV), give vast variation in the estimated results. With this in view, an electronic circuitry, which employs bender and extender elements (i.e., piezo-ceramic elements), was developed. Details of the circuitry and the testing methodology adopted for this purpose are presented in this paper. This methodology helps in determining the resilient modulus of the material quite precisely. Further, it is believed that this methodology would be quite useful to engineers and technologists for conducting quality check of the pavements, quite rapidly and easily.
\end{abstract}

\section{Introduction}

Resilient modulus, $M_{R}$, generally corresponds to the degree to which a material recovers from external shock or disturbance. This property of the material is actually an estimate of its modulus of elasticity, E. In case of slowly applied load, slope of the stress-strain curve in linearly elastic region yields $E$, whereas, for rapidly applied loads (e.g., load experienced by pavements), this would yield $M_{R}$. The resilient modulus can be expressed as

$$
M_{R}=\frac{\sigma}{\varepsilon_{r}},
$$

where $\sigma$ is the applied stress and $\varepsilon_{r}$ is the recoverable axial strain.

$M_{R}$ describes the mechanical response of a pavement base or subgrade to the applied cyclic (traffic) load, and, hence it is considered to be an essential parameter for pavement design. By knowing the resilient modulus for the subgrade soil and the pavement material, the structural behavior of the pavement against traffic loading can be ascertained.
However, obtaining $M_{R}$ is a very difficult task, and it can only be determined by laboratory testing of the material [1-3]. As such, the Long Term Pavement Test Protocol (LTTP) P46 is widely used $[1,4,5]$ for determining $M_{R}$, which in turn requires dynamic triaxial testing on cylindrical cores. Several other (modified) methodologies such as National Highway Research Program (NCHRP) 128A method and Federal Highway Administration (FHWA) method (1) are also employed for determining $M_{R}$. Various empirical relationships, correlating $M_{R}$ to other material properties (namely, California Bearing Ratio, CBR; Limerock Bearing Ratio, LBR; $R$-value and the Soil Support Value, SSV) can also be employed to estimate $M_{R}$. However, these relationships give vast variation between the estimated and experimental results [4-6]. In addition to the material properties, $M_{R}$ value depends upon many of the testing parameters like preparation technique, loading amplitude, sequence of loading cycle and the confining pressure. However, not much attention has been paid by the earlier researchers to corroborate laboratory results vis-à-vis field 
conditions. This necessitates development of a methodology that would yield $M_{R}$ in a convenient way without compromising the field conditions. Under these circumstances, application of a nondestructive methodology, which is based on propagation of mechanical waves, seems to be a better choice $[1,7]$. In recent years, it has been found that some of the nondestructive testing methods (namely, the laser technique, ground-penetrating radar, falling weight deflectometers, mini- or portable lightweight cone penetrometers, GeoGauge, and infrared and seismic technologies) can be successfully employed for the prediction of $M_{R}$ and for the purpose of quality control and acceptance of flexible pavement construction [8]. However, some researchers [6, 911] have found that $M_{R}$, determined from the laboratory testing, differs from the nondestructive testing based analysis.

With this in view, attempts were made to determine the resilient modulus of asphaltic concrete cores by employing piezoceramic elements and an electronic circuitry developed by the researchers at the Indian Institute of Technology Bombay, India $[12,13]$. In addition, complete characterization of these cores was done as a part of the proposed method for determining $M_{R}$. The result obtained from this method was then compared with that obtained from the triaxial loading testing, and it was concluded that piezoceramic elements can be successfully employed for determining resilient modulus in pavement designing.

\section{Experimental Investigations}

2.1. Characterization of Asphaltic Concrete Cores. DAC (Dense Asphaltic Concrete) and SDAC (Semi-Dense Asphaltic Concrete) cylindrical core samples for this study were obtained from the airfield pavements of the two runways of an airport in India. These cores were extracted from the wearing and binder courses of the pavements of these runways. Density-void analysis, Marshall Stability, and Flow value tests were carried out on these cores as per ASTM D6927 [14], and the results are depicted in Table 1.

The Marshall Stability value of the DAC and SDAC specimens, when tested at $60^{\circ} \mathrm{C}$, were found to be $765 \mathrm{~kg}$ and $725 \mathrm{~kg}$, respectively. The flow value of the SDAC specimens was found to be on the higher side as compared to that for DAC samples. The average bulk density of the DAC and SDAC specimens was found to be 2.36 and $2.33 \mathrm{~g} / \mathrm{cc}$, respectively. The stiffness modulus of the mix was determined based on the parameters of the mix (namely, density, air voids, aggregate voids filled with bitumen, and bitumen content), the properties of the bitumen (namely, penetration, softening point, temperature susceptibility, penetration index, and specific gravity), and the properties of aggregates (namely, specific gravity) by using the Shell nomograms [15], as listed in Table 1. The gradation curves for the samples are depicted in Figure 1.

2.2. Measurement of Shear and Compression Wave Velocities. To determine the shear and compression wave velocities $\left(V_{s}\right.$ and $V_{\rho}$, resp.), a simple and cost-effective bender element setup developed by the authors $[12,13]$ was employed. Signal
TABLE 1: Average properties of DAC and SDAC mix of extracted cores.

\begin{tabular}{lcc}
\hline \multirow{2}{*}{ Property } & \multicolumn{2}{c}{ Specimen } \\
& DAC & SDAC \\
\hline Average diameter $(\mathrm{mm})$ & 90 & 90 \\
Average height $(\mathrm{mm})$ & 180 & 180 \\
Bulk density $(\mathrm{g} / \mathrm{cc})$ & 2.36 & 2.33 \\
Air voids $(\%)$ & 4 & 6 \\
Aggregate voids filled with bitumen $(\%)$ & 75 & 66 \\
Bitumen content $(\%)$ & 5.5 & 5.4 \\
Poisson's ratio & 0.4 & 0.4 \\
Penetration value $\left({ }^{\circ} \mathrm{C}\right)$ & 58 & 67 \\
Softening point $\left({ }^{\circ} \mathrm{C}\right)$ & 55 & 47 \\
Temperature susceptibility $(\mathrm{A})$ & 0.038 & 0.049 \\
Penetration index $(\mathrm{PI})$ & 0.347 & -1.299 \\
Temperature difference $\left({ }^{\circ} \mathrm{C}\right)$ & 25 & 17 \\
Bitumen stiffness $\left(\mathrm{N} / \mathrm{m}^{2}\right)$ & 5000000 & 4000000 \\
Specific gravity of aggregates & 2.75 & 2.75 \\
Specific gravity of Bitumen & 1.007 & 1.007 \\
Binder volume $(\mathrm{cc})$ & 12.9 & 12.5 \\
Aggregate volume $(\mathrm{cc})$ & 81.1 & 80.2 \\
Stiffness modulus of the mix $\left(\mathrm{MN} / \mathrm{m}^{2}\right)$ & 931.5 & 750.4 \\
Marshall stability $(\mathrm{kg})$ & 765 & 725 \\
Flow value & 2.2 & 8.35 \\
\hline
\end{tabular}

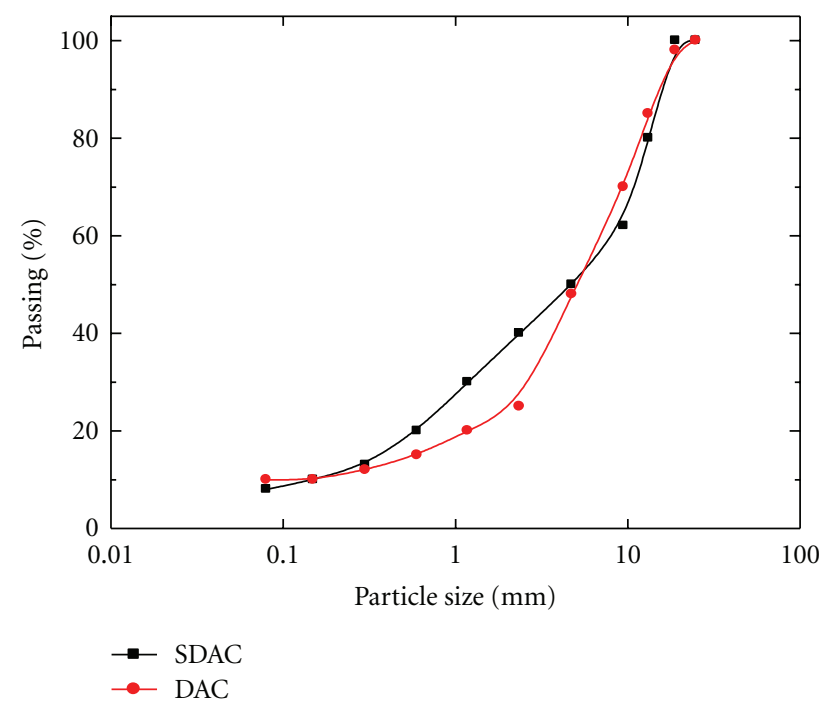

Figure 1: Gradation curves SDAC and DAC samples aggregates.

interpretation and analysis of the results has been done in accordance with the information available in the literature [16-18]. The block diagram of the test setup for measuring $V_{s}$ and $V_{\rho}$ in the cylindrical asphaltic concrete cores has been depicted in Figure 2. As depicted in the figure, on both ends of the specimen, piezoceramic elements (the pair of a transmitter and a receiver) can be fitted. The transmitter is excited with a single-cycle sine wave of certain amplitude, which is generated from a function generator. The receiver 


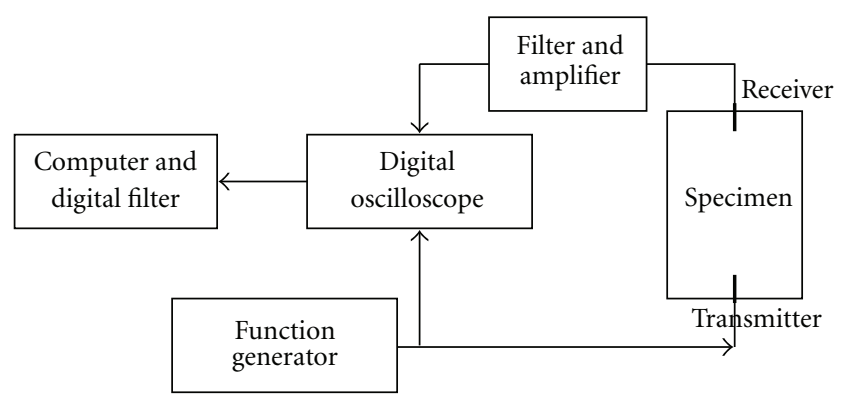

Figure 2: Block diagram of the test setup used for measuring $V_{s}$ and $V_{\rho}$.

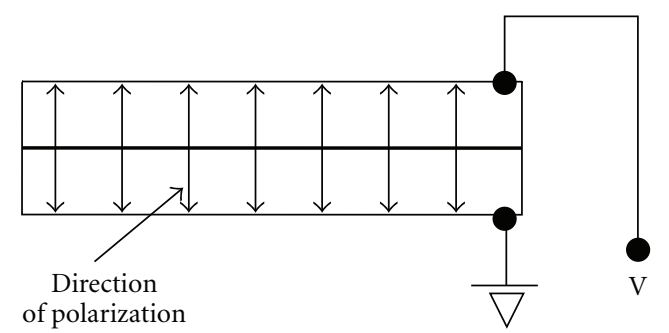

(a)

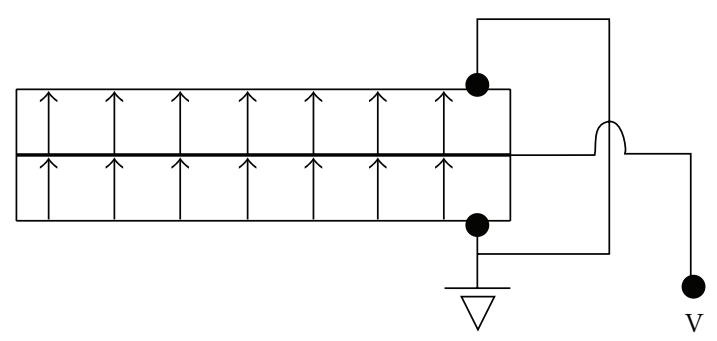

(b)

Figure 3: (a) Series and (b) parallel type configuration for bender elements.

is connected to a filter/amplifier circuitry, which in turn is connected to a digital oscilloscope that also receives a direct sine wave or a step signal from the function generator.

Bender elements used in this study were procured from the Centre for Offshore Foundation Systems, The University of Western Australia. These elements were constructed by bonding two piezoceramic materials together in such a way that a voltage applied to their faces causes one face to expand while the other face to contracts. This causes the entire element to bend and generation of a voltage and vice versa. As depicted in Figure 3, the receiver and transmitter bender elements consist of series and parallel bimorph configurations, respectively. The bender elements in Figures 3(a) and 3(b) were subsequently used as extender element, thus producing $V_{\rho}$, by inter changing the wiring configurations and direction of polarization, as shown in Figures 4(a) and 4(b).

For determining the time delay introduced in the measurements due to the electronics, ceramics, and coating materials of the bender element, calibration of the complete system was conducted. This was achieved by placing the tips

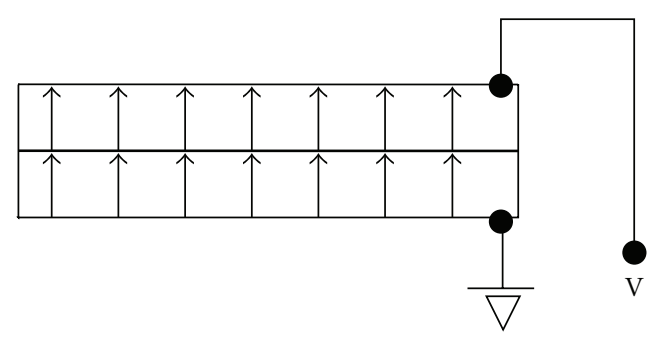

(a)

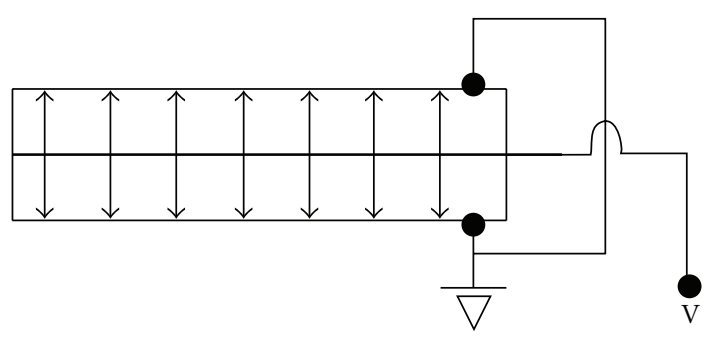

(b)

Figure 4: (a) Series and (b) parallel type configuration for extender elements.

of the two bender elements in direct contact with each other and measuring the calibration time $t_{c}$ between the electrical pulse sent to the transmitter and received by the receiver. It was found that the magnitude of $t_{c}$ is very small $(=5 \mu \mathrm{s})$. In addition to this, $V_{s}$ for an aluminum rod $(160 \mathrm{~mm} \times 25 \mathrm{~mm}$ $\times 25 \mathrm{~mm}$ ), a thermocol ( $82 \mathrm{~mm}$ diameter and $62 \mathrm{~mm}$ length) and a M-30 grade concrete $(50 \mathrm{~mm}$ diameter and $67 \mathrm{~mm}$ length), was also measured [11]. To achieve this, thin slits (about $1.6 \mathrm{~mm}$ wide and $11 \mathrm{~mm}$ long) were created at the centre of each of the two planes, which are perpendicular to the length of the aluminum bar or concrete block. Later, in these slits, which are parallel to each other, bender elements were fitted. For these materials, $V_{s}$ was found to be $3217 \mathrm{~m} / \mathrm{s}$, $280 \mathrm{~m} / \mathrm{s}$ and $1500 \mathrm{~m} / \mathrm{s}$, respectively, which match very well with the values reported in the literature [19]. Moreover, $V_{s}$ and $V_{\rho}$ were measured on some standard materials. Using (2), [20, 21], Poisson's ratio, $v$, when computed for rubber, stainless steel, and cork was found to be 0.5, 0.29, and 0, respectively, matching well with the results in literature [2224]

$$
v=\frac{\left(0.5 \cdot r^{2}-1\right)}{\left(r^{2}-1\right)}
$$

where $r$ is ratio between $V_{\rho}$ and $V_{s}$.

Later, $V_{s}$ and $V_{\rho}$ in the DAC and SDAC specimens were measured. A typical waveform obtained for the DAC specimen is depicted in Figure 5.

2.3. Loading Test. A Humboldt, USA, made master loader system (HM 3000) was used for determining $M_{R}$. This setup facilitates microprocessor-based stepper motor speed control and consists of analogue-to-digital converter with real-time data acquisition; the motor speed can be selected between 0 to $75 \mathrm{~mm} / \mathrm{min}$, with RS-232 interface. 


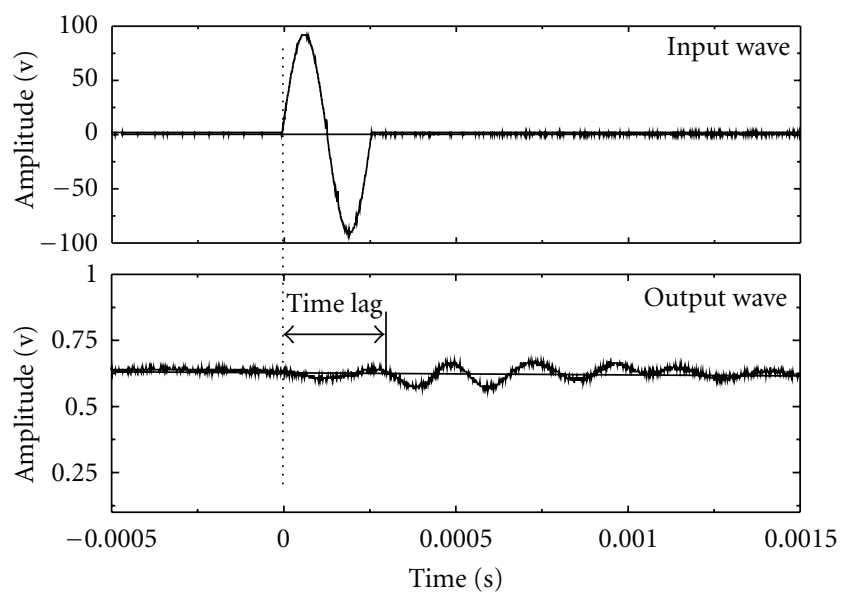

Figure 5: Typical waveform obtained from the test setup for a DAC specimen.

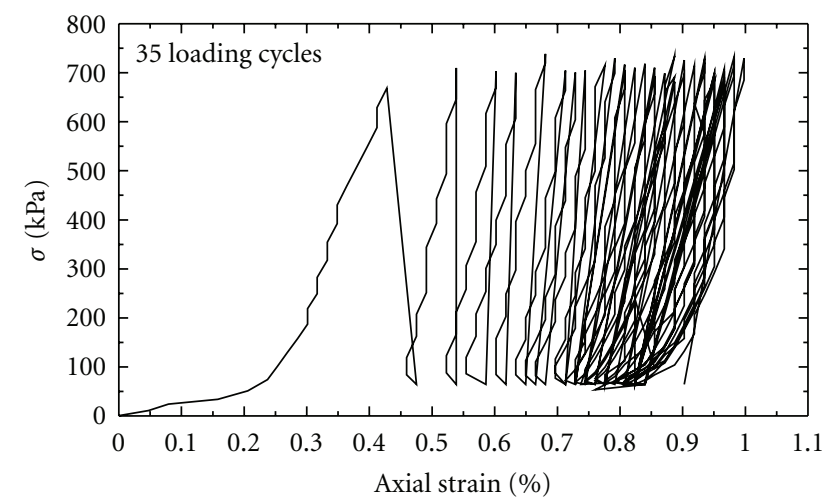

(a)

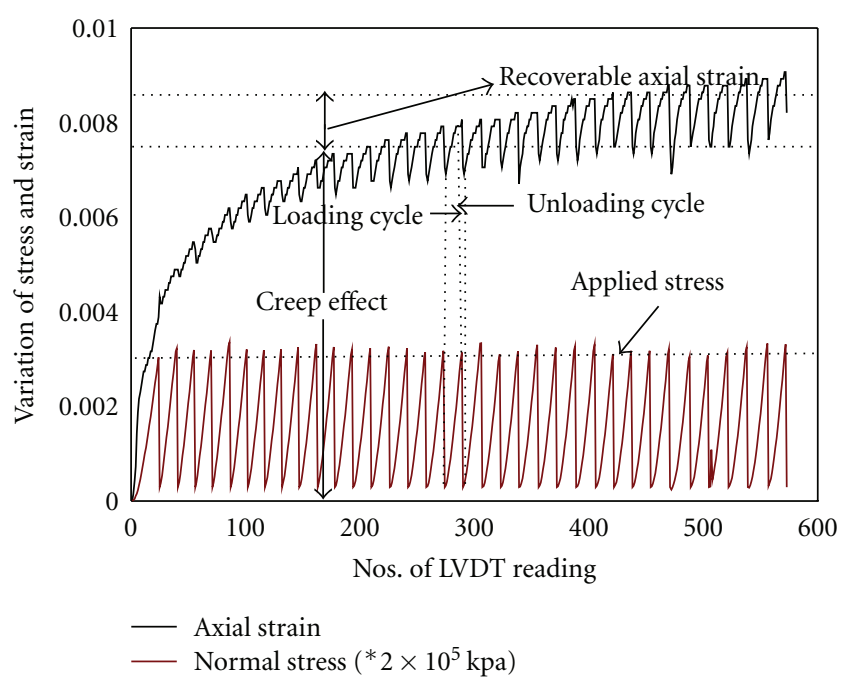

(b)

Figure 6: (a) A typical stress-strain curve obtained for a DAC specimen. (b) Stress-strain variation during loading.
TABLE 2: Shear, elastic, and resilient modulli of different specimens.

\begin{tabular}{lccc}
\hline Specimen & $G_{\max }[\mathrm{MPa}]$ & $E_{\max }[\mathrm{MPa}]$ & $M_{R}[\mathrm{MPa}]$ \\
\hline DAC1 & 775 & 2170 & 1693 \\
DAC2 & 493 & 1381 & 971 \\
SDAC1 & 249 & 698 & 748 \\
SDAC2 & 387 & 1085 & 796 \\
\hline
\end{tabular}

Load was applied on the specimens with the help of computer-controlled user defined test setup program. Before loading the specimens, strain rate was set to $25 \mathrm{~mm} / \mathrm{min}$ and stop condition was set to: "load exceeding $18 \mathrm{kN}$," which is based upon the possible elastic modulus values for these samples. Deformation undergone by the specimens was recorded every $1 \mathrm{~s}$ by employing a Linearly Variable Differential Transducer (LVDT), connected to the computer controlled user defined setup. Each load cycle followed a time lag of $10 \mathrm{~s}$ during which unloading was done. A total nos. of 35 loading cycle was applied to each specimen.

\section{Results and Discussions}

Low strain shear modulus, $G_{\max }$, and elastic modulus, $E_{\max }$, in the specimens were computed as follows $[20,21]$ :

$$
\begin{gathered}
G_{\max }=\rho \cdot V_{s}^{2}, \\
E_{\max }=2 G_{\max } \cdot(1+\nu),
\end{gathered}
$$

Where $\rho$ is the mass density of the specimen. $v$ for the samples was obtained from (2) by using $V_{s}$ and $V_{\rho}$.

A typical stress-strain curve obtained for a DAC specimen is depicted in Figure 6(a). Figure 6(b) exhibits the variation of stress and strain during the loading process. It can be observed from these figures that the variations in these parameters are quite similar to the variation of load and deformation, with time [25]. It must be noted that this concept is widely used for determining resilient modulus by dynamic triaxial testing and applying a haversine pulse loading. Hence, it is believed that the resilient modulus determined by this method would represent the same situation when axle load passes over the pavement.

Recoverable axial strain for the specimens was determined as depicted in Figure 6(b) and using this value, the resilient modulus was determined by using (1). The value of shear, elastic, and resilient modulli are listed in Table 2.

The relationships between $M_{R}$ with $G_{\max }$ and $E_{\max }$ has been depicted in Figure 7. As suggested by earlier researchers $[20,26], V_{\rho} / V_{s}$ and, hence, $\nu$, for a particular type of material (namely, asphaltic concrete, cement concrete or a particular type of rock) remain the same. Hence, $M_{R}$ can be correlated to both $G_{\max }$ and $E_{\max }$, as these two parameters are interrelated by $v$, which is a function of $V_{s}$ and $V_{\rho}$ (ref. (2)). The relationships obtained between these parameters can be expressed as

$$
\begin{aligned}
& M_{R}=2.1 \cdot G_{\max }, \\
& M_{R}=0.77 \cdot E_{\max } .
\end{aligned}
$$




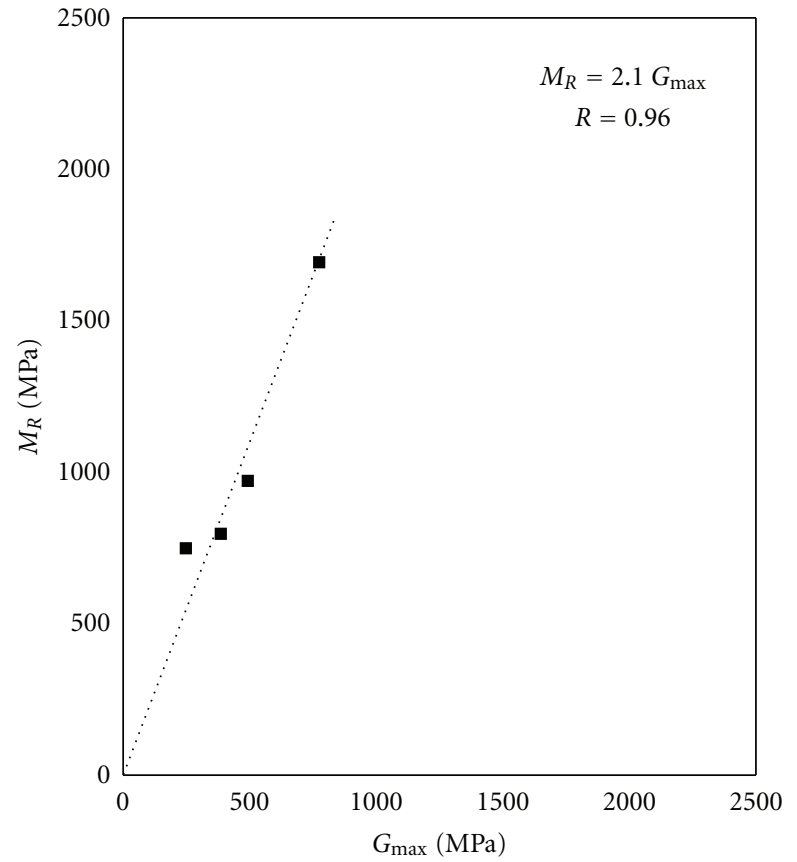

(a)

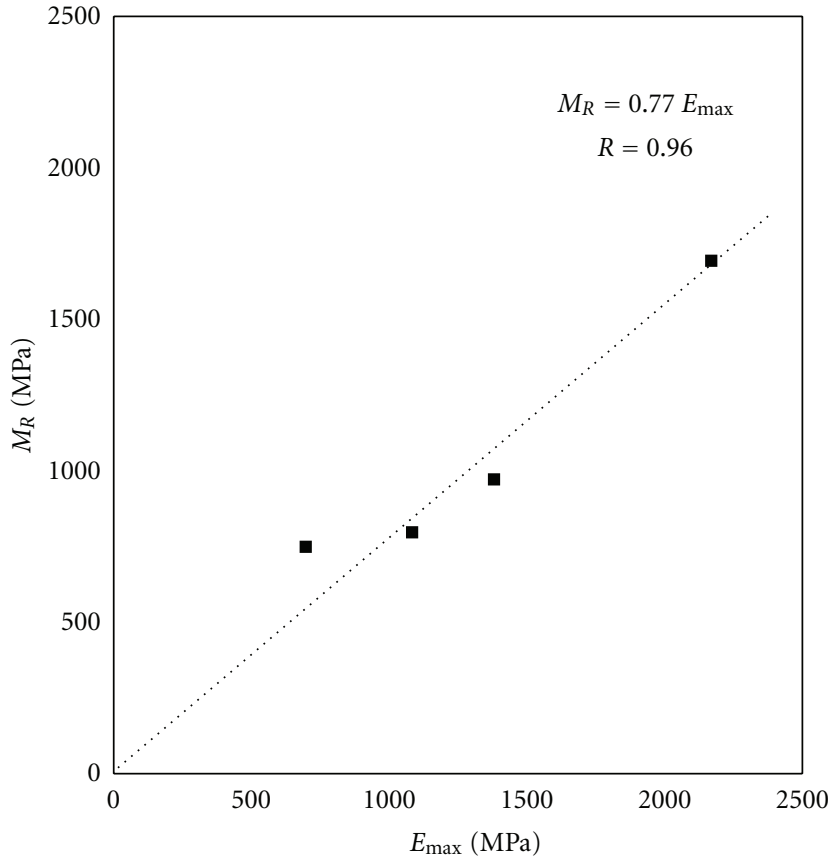

(b)

Figure 7: A comparison between $M_{R}$ with $G_{\max }$ and $E_{\max }$.

This indicates that $M_{R}$ in an asphaltic concrete pavement can be predicted easily with the help of piezoceramic element by measuring $V_{s}$ and $V_{\rho}$.

\section{Conclusions}

This paper presents details of a novel methodology, which employs piezoceramic elements for determining resilient modulus of the dense and semi-dense asphaltic concrete blocks. It has been demonstrated that this methodology yields results in a very short duration and also without employing costly paraphernalia. The results obtained are found to be quite close to those obtained from conventional cyclic tests. However, extension of this methodology to insitu conditions requires further investigations.

\section{Nomenclature}

E: $\quad$ elastic modulus

G: $\quad$ shear modulus

$G_{\text {max }}$ : low-strain shear modulus

$M_{R}$ : resilient modulus

$t_{c}$ : calibration time

$V_{s}$ : shear wave velocity

$V_{\rho}:$ compression wave velocity

$\varepsilon_{r}: \quad$ recoverable axial strain

$\rho: \quad$ mass density

$\sigma: \quad$ applied stress

$\nu$ : Poisson's ratio.

\section{References}

[1] P. Davich, J. F. Labuz, B. Guzina, and A. Drescher, "Small strain and resilient modulus testing of granular soils," Tech. Rep., Minnesota Department of Transportation Research Service Section, University of Minnesota, 2004.

[2] G. N. Durham, W. A. Marr, and W. L. De Groff, Resilient Modulus Testing for Pavement Components, ASTM International, West Conshohocken, Pa, USA, 2003.

[3] B. I. Siswosoebrotho, K. Ginting, and T. L. Soedirdjo, "Workability and resilient modulus of asphalt concrete mixtures containing flaky aggregates shape," Journal of the Eastern Asia Society for Transportation Studies, vol. 6, pp. 1302-1312, 2005.

[4] K. P. George, "Prediction of resilient modulus from soil index properties," Tech. Rep., U. S. Department of Transportation Federal Highway Administration, University of Mississippi, 2004.

[5] A. Yau and H. L. V. Quintus, "Study of LTTP laboratory resilient modulus test data and response characteristics," Tech. Rep. FHWA-RD-02-051, U. S. Department of Transportation, Federal Highway Administration, 2002.

[6] S. B. Seeds, S. H. Alavi, W. C. Ott, M. Mikhail, and J. A. Mactutis, "Evaluation of laboratory determined and nondestructive test based resilient modulus values from WesTrack experiments," in Nondestructive Testing of Pavements and Backcalculation of Module, S. D. Tayabji and E. O. Kukanen, Eds., vol. 3 of ASTM STP 1375, Americal Society for Testing and Materials, West Conshohocken, Pa, USA, 2000.

[7] S. Baig and S. Nazarian, "Determination of resilient modulus of subgrades using bender elements," Transportation Research Record, no. 1504, pp. 79-86, 1995.

[8] H. L. Von Quintus, C. Rao, R. N. Stubstad et al., "Nondestructive testing technology for quality control and acceptance 
of flexible pavement construction," Draft Interim Report NCHRP 10-65, National Cooperative Highway Research Program, 2004.

[9] D. G. Anderson and R. D. Woods, "Comparison of field and laboratory shear modulus," in Proceedings of the Conference on in Situ Measurements of Soil Properties, ASCE, Raleigh, NC, USA, 1975.

[10] J. F. Daleiden, B. M. Killingsworth, A. L. Simpson, and R. A. Zamora, Analysis of Procedures for Establishing in Situ Subgrade Moduli, Transportation Research Record no. 1462, TRB, National Research Council, Washington, DC, USA, 1994.

[11] S. Nazarian, J. Rojas, R. Pezo, D. Yuan, and I. Abdallah, "Relating laboratory and field moduli of Texas base materials," Transportation Research Record, no. 1639, 1998.

[12] P. P. Bartake and D. N. Singh, "Studies on the determination of shear wave velocity in sands," Geomechanics and Geoengineering, vol. 2, no. 1, pp. 41-49, 2007.

[13] P. P. Bartake, A. Patel, and D. N. Singh, "Instrumentation for bender element testing of soils," International Journal of Geotechnical Engineering, vol. 2, no. 4, pp. 395-405, 2008.

[14] ASTM D 6927-06, "Standard test method for marshall stability and flow of bituminous mixtures," in Annual Book of ASTM Standards, vol. 04.08, ASTM International, West Conshohocken, Pa, USA, 2006.

[15] Shell International Petroleum Company, The Shell Pavement Design Manual, Asphalt Pavements and Overlays for Road Traffic, Shell Petroleum Company Limited, London, UK, 1978.

[16] R. Arulnathan, R. W. Boulanger, and M. F. Riemer, "Analysis of bender element tests," Geotechnical Testing Journal, vol. 21, no. 2, pp. 120-131, 1998.

[17] J. S. Lee and J. C. Santamarina, "Bender elements: performance and signal interpretation," Journal of Geotechnical and Geoenvironmental Engineering, vol. 131, no. 9, pp. 1063-1070, 2005.

[18] G. Viggiani and J. H. Atkinson, "Interpretation of bender element tests," Geotechnique, vol. 45, no. 1, pp. 149-154, 1999.

[19] M. A. Ismail and K. I. Rammah, "A new setup for measuring $G_{0}$ using laboratory compaction," Geotechnical Testing Journal, vol. 29, no. 4, pp. 1-9, 2006.

[20] J. C. Santamarina, K. A. Klein, and M. A. Fam, Soils and Waves, John Wiley and Sons, New York, NY, USA, 2001.

[21] X. Zeng and V. Tammineni, "Measurement of small-strain modulus of gravelly soils using oedometer equipped with piezoelectric sensors," in Pavement Mechanics and Performance, GSP 154, pp. 239-246, 2006.

[22] A. Tarantino, E. J. Romero, and Y. J. Cui, "Advanced experimental unsaturated soil mechanics," in Proceedings of the International Symposium on Advanced Experimental Unsaturated Soil Mechanics, Trento, Italy, June 2005.

[23] C. Venkatramaiah, Geotechnical Engineering, New Age International, 3rd edition, 2006.

[24] H. Gercek, "Poisson's ratio values for rocks," International Journal of Rock Mechanics and Mining Sciences, vol. 44, no. 1, pp. 1-13, 2007.

[25] S. A. Tabatabaie, H. Ziari, and M. Khalili, "Modeling temperature and resilient modulus of asphalt pavements for tropic zones of Iran," Asian Journal of Scientfic Research, vol. 1, no. 6, pp. 579-588, 2008.

[26] J. P. Castagna, M. L. Batzle, and R. L. Eastwood, "Relationships between compressional-wave and shear-wave velocities in classic silicates rocks," Geophysics, vol. 50, no. 4, pp. 571-581, 1985. 

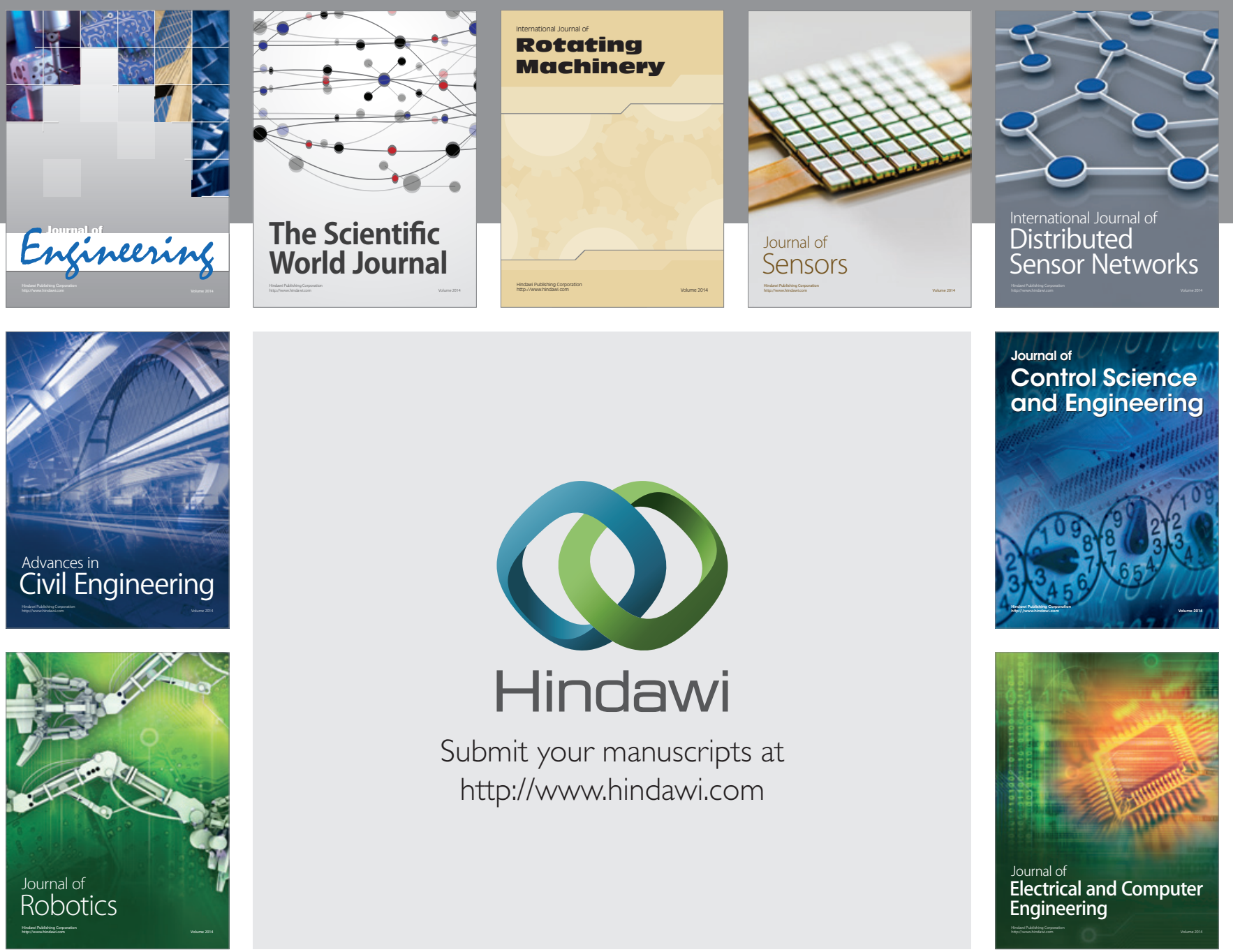

Submit your manuscripts at

http://www.hindawi.com
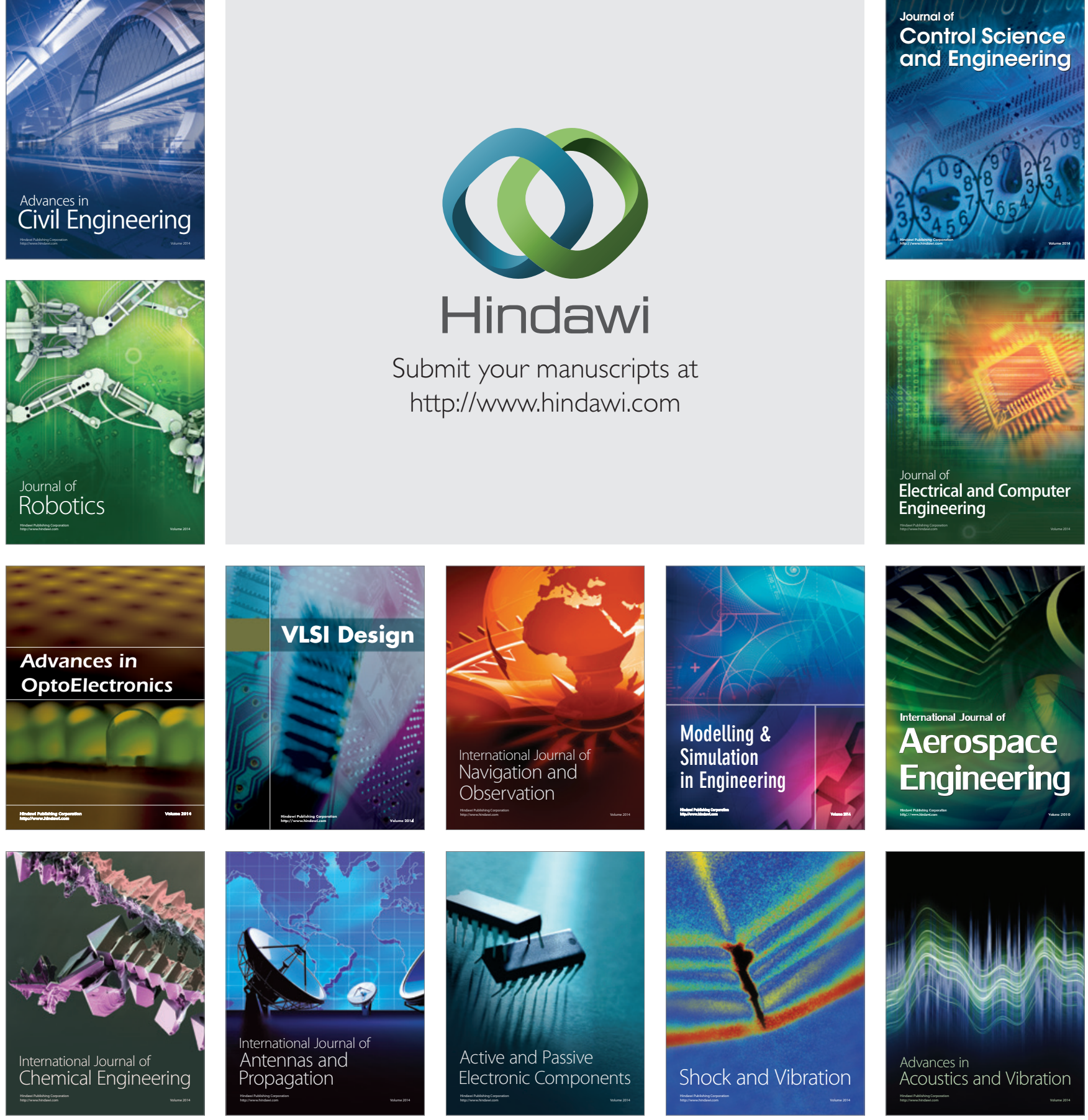